\title{
After the BP Deepwater Horizon Oil Spill: Financial and Health Concerns Among Coastal Residents and Commercial Fishers
}

\author{
Katie E. Cherry \\ Louisiana State University at Baton Rouge \\ Bethany A. Lyon \\ Louisiana State University at Baton Rouge \\ Loren D. Marks \\ Brigham Young University - Provo, loren_marks@byu.edu \\ Pam F. Nezat \\ Louisiana State University at Baton Rouge \\ Follow this and additional works at: https://scholarsarchive.byu.edu/facpub \\ ophert Aflamekner Social and Behavioral Sciences Commons \\ Louisiana State University at Baton Rouge
}

\section{Original Publication Citation}

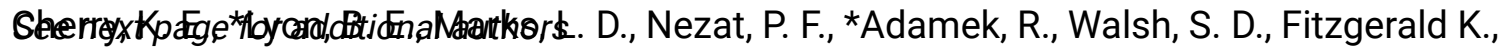
Anbinder, D. R., \& Bernacchio, C. V. (2015). After the BP Deepwater Horizon Oil Spill: Financial and health concerns among coastal residents and commercial fishers. Current Psychology, 34, 576-586.

\section{BYU ScholarsArchive Citation}

Cherry, Katie E.; Lyon, Bethany A.; Marks, Loren D.; Nezat, Pam F.; Adamek, Rachel; Walsh, S. Devon; Fitzgerald, Kristina B.; Anbinder, Dina R.; and Bernacchio, Claire V., "After the BP Deepwater Horizon Oil Spill: Financial and Health Concerns Among Coastal Residents and Commercial Fishers" (2015). Faculty Publications. 4863.

https://scholarsarchive.byu.edu/facpub/4863

This Peer-Reviewed Article is brought to you for free and open access by BYU ScholarsArchive. It has been accepted for inclusion in Faculty Publications by an authorized administrator of BYU ScholarsArchive. For more information, please contact ellen_amatangelo@byu.edu. 


\section{Authors}

Katie E. Cherry, Bethany A. Lyon, Loren D. Marks, Pam F. Nezat, Rachel Adamek, S. Devon Walsh, Kristina B. Fitzgerald, Dina R. Anbinder, and Claire V. Bernacchio 


\title{
After the BP Deepwater Horizon Oil Spill: Financial and Health Concerns Among Coastal Residents and Commercial Fishers
}

\author{
Katie E. Cherry ${ }^{1} \cdot$ Bethany A. Lyon $^{1} \cdot$ Loren D. Marks $^{2} \cdot$ Pam F. Nezat $^{1}$ • \\ Rachel Adamek $^{1}$ - S. Devon Walsh ${ }^{1}$ - Kristina B. Fitzgerald ${ }^{1}$ - Dina R. Anbinder ${ }^{1}$. \\ Claire V. Bernacchio ${ }^{1}$
}

Published online: 18 August 2015

(C) Springer Science+Business Media New York 2015

\begin{abstract}
The BP Deepwater Horizon oil spill is recognized as the largest marine oil spill in U.S. history. In this article, we examine the impact of the BP oil spill on directly affected commercial fishers and indirectly affected residents of the greater New Orleans metropolitan area. A sample of 148 participants responded to an open-ended question on the impact of the oil spill on self, family, and their community at least 12 months after the oil spill began. Content analysis of their narrative text yielded four emergent themes which we present here: 1) Economic Impact on the Seafood Industry and Local Businesses; 2) Commercial Fishers' Financial Future; 3) BP's Response: "Making it Right" or Making it Worse?; and 4) Lingering Worries and Fears: Threats to Fishers' Health and Lifestyle. Implications of these findings for individuals and families exposed to a decade of natural and technological disasters are considered.
\end{abstract}

Keywords BP oil spill · Technological disaster .

Environmental devastation · Hurricanes Katrina and Rita .

Cumulative adversity $\cdot$ Qualitative methods

On April 20, 2010, an explosion on the BP Deepwater Horizon offshore oil rig set into motion the largest marine oil spill in U.S. history. The BP oil spill released an estimated

Katie E. Cherry

pskatie@1su.edu

1 Department of Psychology, Louisiana State University, Baton Rouge, LA, 70803-5501, USA

2 Brigham Young University, School of Family Life, Provo, Utah, 84602, USA
4.9 million barrels ${ }^{1}$ of oil into the Gulf of Mexico over a 3 months period. Consequently, the seafood industry and recreational fishing opportunities for coastal residents in south Louisiana are in peril, together with the other Gulf States that were directly impacted (Lee and Blanchard 2012; Mong et al. 2012). For those who live and work in coastal communities affected by the BP oil spill, the longterm effects remain uncertain. For commercial fishers and their families who are economically dependent on Gulfsupplied natural resources, the uncertainty and adverse ecological effects which threaten their fishing lifestyles and cultural heritage may be devastating. Understanding the financial, social, and mental health impacts of the BP oil spill on vulnerable populations who have been directly affected by this event represents a pressing challenge for researchers and clinicians (Osofsky et al. 2011).

Prior research has examined long-term threats to mental health for commercial fishermen affected by the 1989 Exxon Valdez oil spill (Arata et al. 2000; Palinkas et al. 1993; Palinkas 2012). For instance, Arata et al. (2000) studied commercial fishers 6 years after the Alaskan oil spill. Their findings suggest that those who suffered economic loss after the spill showed higher levels of depression, post-traumatic stress disorder (PTSD), and anxiety than those who did not experience this loss. Other evidence has shown that Gulf Coast residents who were more economically affected due to greater loss of income were more likely to report high levels of distress from the BP oil spill (Cope et al. 2013; Grattan et al. 2011; Mong et al. 2012). Gill et al. (2012) found that economic factors, commercial ties to renewable resources, exposure to

\footnotetext{
${ }^{1}$ According to the U.S. Energy Information Administration, one barrel of oil is 42 fluid gallons. See: http://www.eia.gov/tools/faqs/faq.cfm?id= $327 \& \mathrm{t}=9$ (Retrieved 02/20/2015).
} 
oil, family health concerns, and age predicted psychological stress within the first 5 months of the BP oil spill, replicating similar outcomes for the 1989 Exxon Valdez oil spill disaster (see also Gill et al. 2014). Taken together, Gill et al.'s results, among others based on quantitative methods (Arata et al. 2000; Cope et al. 2013; Grattan et al. 2011), illuminate resource loss as a critical factor in post-disaster psychological reactions, consistent with Hobfoll's Conservation of Resources theory of stress responses (Gerhart et al. 2015). The present investigation was designed to advance this literature using a qualitative approach to permit greater insight from the perspective of those whose lives and communities have been impacted by the BP oil spill.

The present study is part of a larger, mixed method research project on long-term recovery after the 2005 Hurricanes Katrina and Rita, which devastated the U.S. Gulf Coast. Our first findings based on a quantitative approach indicated that low income and being a commercial fisher were associated with increased risk of depression (Cherry et al. 2015). A follow-up study to address commercial fishers' strategies for coping with oil spill stressors revealed that storm-related stressors and lifetime traumatic events predicted different styles of coping, although only avoidant coping was associated with increased risk depression and posttraumatic stress (Cherry et al. 2015). In the present study, we examine how the oil spill has affected individuals, families and their communities using a qualitative approach to provide greater depth of understanding of individual-level and community-wide concerns. Qualitative methods have historically been used in mental health services research (Palinkas 2014). More recently, qualitative methodologies based on grounded theory (see Marks et al. 2009) and mixed theory approaches (see Osofsky et al. 2014) are gaining acceptance in the social sciences and can be flexibly applied to study post-disaster psychological reactions (e.g., religious coping, Marks et al. 2009; Tausch et al. 2011; volunteer behaviors, Silva et al. 2009). We employed qualitative analysis of narrative data obtained from structured interviews with coastal residents to identify recurring core themes that provide rich, textured insight into the lived experience coping with stressors related to technological disaster (Slife and Williams 1995). Such insights are valuable to advance existing theory on traumatic stress effects and are also integral to the development of evidence-based interventions to lessen long-term adversity for those whose lives have been challenged by natural and technological disaster.

Our initial qualitative analyses yielded seven core themes. The first three themes, reported elsewhere, were unique to commercial fishers' narrative responses. These themes included: (1) uncertainty related to how this spill will end and what will become of their fishing careers and lifestyle, (2) environmental devastation and threats to the ecosystem and coastal wildlife, and (3) a pile-up effect where the BP oil spill is the newest stressor added to a long list of adversities over the last decade (Lyon et al. 2015). In this article, we present the four remaining core themes related to economic, financial, health, and lifestyle matters. To address the reliability and generalizability of our earlier findings, we also include here a comparison group of coastal residents (nonfishers) who were not directly affected by the BP oil spill. The inclusion of non-fishers in the study sample is desirable for at least two reasons. First, earlier sociological research documents widespread social impacts of the oil spill, highlighting the constructs of place attachment, social capital, and corrosive community as important for understanding post-disaster mental health (Gill et al. 2012; Lee and Blanchard 2012). We anticipated that the non-fisher responses would further illuminate these community- level factors, permitting novel insight from the perspective of individuals and families who live with the daily realities of the oil spill. Second, the inclusion of the fishers' responses, together with those of less economically impacted coastal residents (non-fishers), increase the breadth of inferences warranted and thereby enhance the ecological validity of the present findings.

\section{Method}

\section{Participants and Procedure}

In all, 148 persons were included in this study. All were exposed to the $2010 \mathrm{BP}$ oil spill by virtue of their geographic proximity to the Gulf Coast. They had also experienced catastrophic losses of homes and property in the 2005 Hurricanes Katrina and Rita, which are documented elsewhere (Cherry et al. 2015). Eighty-four participants (non-fishers) resided in the greater New Orleans Metropolitan area $(M$ age $=59.8$ years, $S D=14.2$, age range $=22$ to 83 years, 39 men and 46 women). They were indirectly affected by the oil spill and were recruited from church groups, civic organizations, and a senior center where the first author gave informal talks about the project. A recruitment flyer seeking research volunteers and mail-in (pre-stamped) postcards were distributed after each presentation. Follow-up telephone calls were made to those who returned postcards or self-selected to participate based on word of mouth referrals. These individuals lived through the 2005 hurricanes and had either relocated from their preKatrina community to a new place of residence or returned and rebuilt their home post-disaster.

There were 64 commercial fishers and their family members $(M$ age $=54.7$ years, $S D=15.7$, age range $=21$ to 90 years; 34 men and 30 women). They were recruited from multiple sources in St. Bernard and Plaquemines parishes (counties) and through a mailing to the United Commercial Fishermen's Association (UCFA). The majority of the 
sample worked in the commercial fishing industry and very few worked in the oil industry (Cherry et al. 2015 for occupational data).

Informed consent was obtained for all participants based on the protocol approved by the LSU Institutional Review Board. All were assigned a three-digit number to protect anonymity; indirectly affected former coastal residents in the $100 \mathrm{~s}$, current coastal residents in the $200 \mathrm{~s}$, and current coastal fishers in the 300 's. The former and current resident groups did not significantly differ on multiple indices of storm exposure and mental health reported elsewhere (Cherry et al. 2015); therefore, we combined these two groups in this study.

Interviews were conducted in participants' homes or in community locations (e.g., a marina, a local bank, and school buildings) in two sessions (or more, if needed). In the second session (at least 1 week later), participants answered this open-ended question:

"Have you been directly affected by the recent oil spill in the Gulf Coast? If so, in what way? Please tell us how the oil spill has affected you, your family, and your community."

Their responses were recorded on a digital voice recorder; digital voice files were transcribed verbatim and doublechecked by different student assistants for accuracy. Final transcription audits were carried out for each voice file by two senior research assistants to ensure integrity prior to printing paper copies for qualitative analyses. Of the 85 coastal residents (non-fishers), three couples answered jointly for a total of 82 interviews. Of the 64 fishers, four couples responded jointly and one participant declined for a total of 59 interviews.

\section{Qualitative Analysis and Coding}

Narrative data were content analyzed in a manner consistent with grounded theory methodology (Strauss and Corbin 1998; see also Marks et al. 2009). One coding team of four members (one graduate student, three undergraduate students) met weekly during the summer and fall semesters of 2013 to carry out the open coding process. Each week the four coders discussed the prevalent ideas and themes covered in the 10 12 interviews coded per week, until all interviews had been coded by a minimum of two coders each. Participants' responses were analyzed using open and axial coding, two techniques from grounded theory methodology (Strauss and Corbin 1998). We conducted team-based analyses to enhance the reliability and validity of findings. In all, seven themes pertaining to the impact of the oil spill on current and former coastal residents were revealed; three are reported in Lyon et al. (2015) and four are presented next.

\section{Findings}

Four themes in connection with the economic impact, financial hardships, and long-term threats to health and lifestyle emerged from our qualitative analyses of coastal residents and commercial fishers' responses. Each of the themes is addressed by both fishers and non-fishers, but with different degrees of concern. The coastal residents recognize the impact the oil spill had on their friends and neighbors who are economically tied to the commercial fishing and seafood industries. The level of personal impact and relevance the spill had on each individual is the primary distinction to be drawn between those who reportedly fish for a living (numbered in the 300s) and those who do not (100s and 200s). Three of the themes presented next relate to economic and financial hardships and worries. The fourth theme relates to perceived threats to health (broadly defined) and fishing lifestyle. We turn now to these four themes with numerous excerpts of original, primary data for support and illustration.

\section{Theme 1 - Economic Impact on the Seafood Industry and Local Businesses}

The severity of the oil spill on the seafood industry is captured by the following commercial fishers' descriptions:

327: In the beginning the crabs were dying; you'd pick up [your crab traps and they] would be full of dead crabs or the crabs, they just have holes in them. It's just, they $[\mathrm{BP}]$ destroyed the fishing industry here and they don't want to be responsible for it.

320: Well, yesterday we... kind of spot checked some of the state lease and there's no way we're going to make a living on that. And...I actually called the biologist today in Baton Rouge. His name is M. L., ${ }^{2}$ spoke to him, and...we spoke about oysters and how bad it looks. Told him what I found and he said he'd never seen the industry or the...product that we had look this bad.

The economic impact has been distressing to commercial fishers. A fourth-generation oyster family member illuminates the breadth of the problem, beginning with the imposed ban on fishing in the U. S. Gulf, followed by the fresh water diversions:

324: Yes, we have been directly affected by the oil spill. We weren't able to work as far as fish[ing] for oysters for what, about 9 months or so? And a lot of the oysters died because of the fresh water diversions that they let run in an effort to try to keep the oil away. So, that's greatly affected our business and...even though we are back in

\footnotetext{
${ }^{2}$ Any participant names, or names/initials that participants referenced have been replaced with pseudonyms in this article.
} 
business now, things are open, there are some oysters still alive that are harvestable but we lost a lot, the consumer confidence ...the safety of our produce is, especially nationwide, is very affected. People don't want to eat gulf oysters because they feel that they're tainted by the oil and they don't want to take a chance even though the government says it's perfectly healthy, they run all kind of tests, but you can't change peoples' perceptions.

Other fishers spoke of the adverse effect of the dispersants on the growth of oysters, providing a developmental perspective on how the chemical cleanup effort and freshwater diversions have affected seafood production:

341: The oil spill really screwed us up bad, [big] time... It is sad, they sprayed that chemical to dissolve it and sink it and it destroyed all the shells and all the mud and all the bottom of the waters, all of what the small bacteria and the plankton and that eats and feeds on, is all dead and polluted now. So now your baby oysters, your baby shrimp, nothing can survive down there no more.

347: Oysters are something... it ain't like your other seafood. It takes a long time to grow. And then, after that, they ran a lot of fresh water for that BP spill to try to push the oil out. And when they did that, it made the mussels grow on the oysters that were... alive.

Perceptions of health dangers were noted in some of the interviews with indirectly affected participants, which are reflected in the following quotes:

220: I don't feel safe eating the seafood no more. I haven't eaten any of it that I can remember ... I think it's going to affect the community... once they [BP] leave, and if people start getting sick from this stuff and people start coming up with cancer in different parts of their bodies and they can prove it went back to that [dispersant]... then you are going to see the whole fishing industry fall apart along the Gulf Coast and you're not going to have anything to make a living at.

Some of the participants did not feel this way, however. They still carried on as a regular consumer, trusting the discretion of the fishers to screen seafood for quality.

222: It hasn't stopped me. I don't think they would put anything out that was harmful. I think everything is checked very carefully. And I have no problems with eating the seafood.

232: The fishing has been excellent. The good thing about it is you don't have any competition. Because some people still don't want to eat the fish. ... [S]ome people's wives said, "Don't bring any of that stuff home."

The wavering trust in the seafood by the general public is an obvious concern for commercial fishers. The oyster crop takes a long time to mature for harvesting, and fishers have seen a reduced demand for their product. As one fisher noted:

304: What we really have to worry about is what's going to happen in the future here if the people are going to eat the seafood, if they're going to want to eat oysters and you know, [in] this community [we] have a lot of oyster fishermen and shrimpers.

Another oyster fisher explained:

310: I was getting 45 dollars a sack if I wanted to sell, if I could have caught something last Christmas, and now I cannot get but 24 [dollars] a sack. And I cannot sell them. Nobody wants, you know, more than a 100 sacks at a time... a week. And I could sell 500 sacks a week before. So, the economic impact is just as bad as the biological impact.

The impact the oil spill has had on the natural seafood resources (crabs, oysters, fish, shrimp, etc.) is yet to be determined long term. A few fishers clearly note that the loss of any of the major branches of the seafood industry would be a catastrophe for the region, and for commercial fishing as a whole.

303: The ripple effect of this is losing any one of these five [seafood industries] is just incredible, because it just, I mean it's kind of like, like an atomic bomb hitting with shock waves going out there. I mean listen, you know what I mean?... It's just a, it's just a number of things that could go wrong. If we lose one, just one, keeping our fingers crossed we lose none. If we lose one [of the five industries], it's going to be detrimental to the whole state. This whole state is going to feel it. [And] not [just the] state, the country will feel it. Louisiana, the oyster industry in Louisiana, St. Bernard Parish and Plaquemines Parish[es] are the biggest producers of oysters in the United States.

360: The resource has been severely impacted, and that is the most, I guess, that is the most serious thing that we are waiting to see...whether it comes back, the resources, the natural resources, the production of oysters that we see, the resource rebound. We have not seen it yet, and that is disturbing us. [It is] disturbing the people with the state, the oystermen, the Wildlife and Fisheries, the biologists. 
In summary, fishers and the community residents are apprehensive and anxious for the future of the seafood industry. The next quote is illustrative:

324: So, it's greatly affected our, the market, our sales are way down nationwide than what they were before, so, and that's going to take years for that to, that confidence to come back. Hopefully it will. And because we, our community, is largely a fishing community, especially down in Empire and the lower end of the [Plaquemines] parish, the whole community is hurt. And it, just made, it's made us lose confidence in staying in the oyster business as a viable way to make a living.

In Theme 1, we have discussed the past and present economic impact of the BP Deepwater Horizon Oil Spill in Louisiana coastal communities. In the next theme, we present the perspectives, perceptions, and profound concerns of "insider" participants as they look to the future of their own fishing and finances.

\section{Theme 2 - Commercial Fishers' Financial Future}

Fear and worry about surviving and making a living as a commercial fisher is a new feeling brought about by the 2010 oil spill. As mentioned earlier, initial restrictions imposed during the first 2 years after the spill shortened the seasons considerably which directly affected fishers' finances, as illustrated in the next quote:

341: We had the worst trawling season ever, the worst dredging season. Dredging usually opens the Labor Day ... I mean, the first Monday after Labor Day in September and it closes April 1st. This year instead of the first Monday after Labor Day, September, when did it open? ... it opened the week of Thanksgiving, Two and a half months late. And instead of closing April 1st, when did they close it?.. February 1st . . . alright, two and a half months early. So instead of having a 7 months season we had a like a 2 months season [in 2011]. So and then last year we had no season [in 2010]. So in 2 years, we had 2 months. So, we got people now that are fishermen, and fishermen live on money that they [earn fishing], you make money and you save it. And then you learn how to live with what you got. And when the next season comes you have saved enough to make it to that season. So, now you got fishermen that have depleted their resources that they have saved. So, now you have no seasons that are open.

Fishing was regarded as a respectable livelihood in southern Louisiana, with little or no worries about scraping by paycheck to paycheck. Post-spill, this no longer seems to be the case. Fishers are struggling to stay financially afloat.
354: ...A lot of the guys that are still crabbing, they are just making a fraction of the money that they were making before the spill. Back then, guys would not even think about running 800 traps. Now, they got to run 800 just to survive.

326: [E]verybody [in seafood] is worried about [money]. And that bothers me a lot because I worry about...paying for everything I own... not that I live an extravagant lifestyle, I am just a normal person, but there are a lot of things I like to do and I have to cut back because... we cannot afford it right now. So, to me, in a way [the spill] could be worse than Katrina.

Many of the commercial fishers had to take on different jobs in order to pay bills and survive economically in the wake of the oil spill disaster. These jobs were not seen as rewarding to the fishers, rather just a way to make ends meet. Their passion for fishing is not "just a job," it is a way of life, a major part of their heritage and culture (Cherry et al. 2015a).

345: There is something I wanted to add. ...[T] man is eventually going to have to move on to feed his family.... [E]ventually they'll get hungry enough to go look for food somewhere else. And that's going to cost somebody their heritage, and their life. But in a couple of months that might be me.

332: You know, and I get up every morning and go do something I don't particularly want to do but that's what I do to pay my bills and put food on my table because I can't work as a fisherman...

320: I'm not sure what to do right now... [In the past], things will always seem like they pop up .... But [this time]...I see it coming to an end really, really fast here.

And...I'm just...really kind of scared. I mean, it costs a lot of money to live...

The financial woes of the fishers were noted not only by themselves, but also by the less affected (nonfishing) community members. They have seen the struggle the fishers have been going through to try to make ends meet from the outside. Their compassion and sympathy for the local fishers is evident in the following excerpts:

201: I hadn't seen that look on people's faces in a long time, just... they feel helpless, they don't know how they're going to cope with their family [struggles]...just not knowing what their future's going to bring, how long it is going to take. 
250: My hurt is seeing others hurt, who have been directly affected. I've prayed and I'm now believing God [will] restore their loss and make them whole again.

Some of the financial pinch was alleviated for fishermen that were hired in BP's Vessels of Opportunity Program. This program was part of the clean-up effort, and utilized many of those who were already intimately familiar with the waterways.

314: But, I feel like how the oil spill affected me, I told you last time working on the oil spill was really fun. I enjoyed it. It was the most money I've ever made in my life and it was like play time all of the time. We just drove the boat, $\mathrm{d}[\mathrm{id}]$ what we had to do. Whatever they told us to do, we did it. It was easy... it really was.

349: Yes, ...the environment is being affected, but also after the BP oil spill, okay, they took commercial fishermen, BP hired commercial fishermen that could not work because of their oil spill, and provided them with jobs that supplied them with more money in the past [two] years, that they couldn't have made in 15 years.

The Vessels of Opportunity program was not a permanent fix, however, just short-term employment offered to a small selection of the local fishers. While the Vessels of Opportunity did help clean-up portions of the spill, it did not fix all of the financial concerns fishers faced, especially long term. As one fisher explained:

321: They gave us a lot of money and hired us and we did good for about 6 months... about 6 months we did real well. But since last Christmas, I am still in the hole.

In Theme 2, we presented Louisiana fishers' thoughts and concerns as they cast a concerned eye to their future finances and fishing efforts. The third theme, presented next, more specifically addresses the stress and worry associated with the oil spill and among those in the fishing community and frustrations related to BP's corporate response.

\section{Theme 3 - BP's Response: "Making it Right" or Making it Worse?}

A discussion of BP's corporate response to the oil spill requires a brief note on the media campaign which included a public service announcement of BP's plan to "make it right." To provide additional historical context, we note that BP had spent 93 million dollars on advertising from April through July, 2010 (CBS 2010). Both popular media as well as economics researchers discussed the actions taken by BP post-spill (Balmer 2010; CBS 2010). Some researchers believe the attempts made by $\mathrm{BP}$ to undo the negative effects caused by the oil spill are lacking in sincerity (Balmer 2010). Balmer discusses corporate steps taken after major disasters, and their motivations behind these steps. Ethical identity in corporate marketing is required for businesses in today's world, to claim they are a good global entity (Balmer et al. 2011). Balmer and colleagues state that the claims made by BP that they (BP) will make reparations postspill are thought to be lofty and unattainable, and "divorced from reality" (Balmer 2010; Balmer, et al. 2011).

This feeling of disconnect between what is said and what is done was apparently on the minds of many participants in our study. The following quotes are illustrative:

302: Yes, they should have [listened right away], but nobody wanted to listen to a fisher. BP did not want to hear nothing we had to say, or suggestions of what we had to say, or where we need to put the buoy[s] at. And all that, see, they marked the areas by airplane where they thought that the oil has gone. But we know, we fishermen, we know where the deep canals [are]. We know where the tide flows the strongest and all that. We know all this and yet they did not want to hear it. They did not want to hear it.

329: [Now we are dealing with] more of the not knowing what is going to happen to you the next day, and more mismanagement by a big company that the government backs up. They [BP] put commercials on TV saying that they doing the right thing and all...[Well, that's] not even close [laughs].

341: You go out there and drop your rigs and [you're] pushing the trawl and your rigs come up and it is just full of oil...there is nothing that can live in [that mess]. But they do not put that on TV and nobody sees that.

310: During the BP [situation], everybody was getting paid quite a lot of money and a lot of money was going around. Well, as soon as they capped it off and things got down, 6 months down the line, there was no more BP money, [and no] shrimp because [we] could not sell them, [and no] oysters... you do not have any. So without that economic stimulus, the community is failing... just as we predicted.

302: BP promised us that if anything happened on the job, to our boats, anything, that they would take care of it. If anything goes wrong, they [were] going to take care of it. And they didn't and didn't stand up to their promises. And the parish, I guess they're paid off [for] whatever they did.

The worry, fear, and anger were also recognized by those not directly affected. Even the non-fishing coastal residents 
expressed concerns about the future of their community and how BP is handling the situation.

262: When it affects one part of your community, it affects all of your community. ... One little...thing can affect a whole group of people. It's like throwing a rock into a pond and you get the ripple effect to the whole pond. And, I think it's like that with any disaster.

132: I realize that this problem can have a .... a scope that is very broad and that can be very far-reaching. Maybe not today, but down the line. You just don't know how that's going to affect an ecosystem or...the community of life in the water. And, I mean BP can really try to estimate the damages as much as they say, but I mean they can't really quantify that, you know? So, I think the scope of its problem is pretty large.

254: So, if you...take a gazillion barrels of oil and put it in the Gulf of Mexico, and you...get on TV, and you're going to tell me that you're environmentally conscious and your idea of fixing it is to go get a bunch of chemicals to drop on it so it sinks .... and then you tell me we've got all these boats, and we're paying all this money, and we're making BP do all these things, and you're down there every day and you see the boats stay tied up every day [it makes you wonder]...

254: Most of the boats and things that they hired never left the dock. It was all there just for the journalists to take pictures of.

Even though the vast majority of our participants were displeased with BP as captured in the previous interview excerpts, some participants still identified positive aspects of the situation, as reflected next.

349: [Some] people have things that they never would've had in their life because of [the] BP oil spill in lower Plaquemines Parish... [Some] people made very good money and were able to place themselves in places that they may never have been because of BP.... [A]nother silver lining was that the oil spill did happen, because there were commercial fishermen that had nothing that was still living in FEMA trailers [from Katrina] and couldn't make a living to move their family into something else. [For them], going to work for BP actually helped and made them get back on track like they were before Katrina.

349: Yeah, that's fine, [oil accidents happen] once every so many years, okay? But look how many people that [the oil industry] provides a good quality of life to. How many people are employed by oil companies that have a great quality of life, myself being one, my younger brother being one. A lot of people in lower Plaquemines Parish...before Katrina, worked for oil companies. So everybody likes to attack them when something happens, but they don't look at the long-term of how many people ha[ve been] going 30, 40 years, working for oil companies, been able to retire, and maintain a good quality of life. I guess...it kind of irritates me that people attack the oil companies because I'm an employee of the oil field.

146: The company I work for, along with four other companies, is spearheading this new response team on the Gulf Coast, this new response ship that can take care of these problems long before it got this bad. So, it affected me in a good way knowing that the company I work for is going above and beyond to make things a little bit better and to learn from it. Okay? That's the most important thing. When we make a mistake we learn from it.

With exceptions like these just noted, most of the participants seemed annoyed and resentful that BP did not take care of the situation as they had promised to. The following two statements are illustrative of the general resentment and disdain.

352: I mean, I just wish they would do what these people say they are going to do, for the sake of our fishing and the rest of us. I mean, we did not ask for this to happen. We get out there and we try to survive everyday through this. I mean, our crab industry is suffering, our oyster industry has been devastated. I mean, it is disgusting. They act like we do not exist, you know? "Here. Here is a couple of dollars, shut up." Well, what about everything in my future you just destroyed?

345: There still is a big psychological pondering. What are the long-term effects going to be? A lot of resentment to the fact that they swear they're going to make it whole and they treated us right at first, [but] now all the communications and everything just kind of stopped. They started to pinch pennies and get real nit-picky, making you prove things that are...impossible to prove at this point.... So we felt like we were played.

Participants' reports indicated that some fishers' BP settlement claims were being denied, forgotten, or inadequate. Meanwhile, others that were indirectly affected were getting settlements processed and paid; which was seen as very unfair in the eyes of the fishers trying to just scrape by. 
332: BP is not going to drop bucket loads of money in my lap...they've denied every claim. They denied my loss of income, they denied my health [benefits], they denied my loss of value.

314: [There are people that are] abusing the system and everybody coming out of the woodwork to try to get that money. They try to get their hands on that money, which is sickening really to the people that actually need it and aren't getting what they deserve.

A final statement by one participant seemed to reflect the sentiments of many of the fishers who feared that the oil spill may be the final blow to their way of life. He said of the BP spill:

340: What the oil spill did was ruin the good name of Louisiana seafood and basically that was the only thing we had in all of the global market was that. Our seafood was the best. People still think there's oil down here and there probably is. But nobody wants to talk about it ... none of the officials [will talk about it]. It ruined my lifestyle. Getting compensated is not the same as not having it happen to you at all. Katrina made everybody move and now the storm's finishing us off.

Theme 3 focused on participants' specific perceptions of BP's immediate and longer-term response to the oil spill. In the fourth and final theme, we move from a corporate focus to address additional lingering and longer-term concerns that these fishing-based families wrestle with as they face the future.

\section{Theme 4 - Lingering Worries and Fears: Threats to Fishers' Health and Lifestyle}

The possible future outcomes for the commercial fishermen affected by the BP spill described next are not pleasant. Interpersonal concerns for one's own health and the health of loved ones after exposure to dispersants, coupled with worries about the long-term viability of the fishing lifestyle adds to the stress and uncertainty coastal fishers are experiencing. According to the Journal of the American Medical Association, immediate negative health effects from exposure to oil and chemical dispersants have also been found (Solomon and Janssen 2010). Oil components on the surface of the water evaporate and can cause respiratory irritation, as well as central nervous system depression. Exposure to these oil components can have very serious health effects, not limited to leukemia, birth defects (at high doses), and cancer (Solomon and Janssen 2010). Close proximity to burning oil and dispersants adds to the list of serious health concerns. These dangers are not to be taken lightly, but risks are heavily dependent on the degree and duration of exposure (see McCauley 2010, for related discussion). Potential indirect health effects from contaminated seafood consumption was, and in some cases remains, a serious concern for the seafood industry in the Gulf (Solomon and Janssen 2010). Acute symptoms reported by a majority of those helping in the oil clean-up efforts include "headaches, dizziness, nausea, vomiting, coughing, respiratory distress, and chest pains" (Solomon and Janssen 2010, p. E2). The reality of these health dangers were faced by many of our participants, as discussed here.

317: We did not know we were going to be exposed to these chemicals that we were fishing [in]. That is physical injury, very physical, what we have been through. And physically, what happened was that...our toxin levels in our bodies [have been raised]... and the reason we know that is because we did hair samples and we know how high our toxins are in our bodies from hair samples. You know, not knowing if we are going to get cancer or whatever, get sick in the next few years, is something that is on all of our minds.

361: The dispersant actually releases the clot from your arteries, and breaks it loose. It gets to moving and forms clogs...like a high dose of cholesterol medicine, it knocks out your clog from your arteries, it's just a big strong shot of whatever it is.

204: You walk out and you could just smell, the kind of like a diesel smell, but a real strong diesel smell. So of course for me with breathing issues, I just stay inside, you know... and I'm wondering if that's not part of what the reason I'm having problems right now.

One participant, 332, had a very close encounter with the chemical dispersants and the oil. Her health has reportedly suffered from this exposure as noted by the following excerpts:

332: ....and, we went across a patch that was being sprayed with dispersant and I inhaled... and developed chemical pneumonia. So, I spent almost the whole entire month of July in Arkansas being treated. I had to do sessions in the hyperbaric chamber... I had a lot of lung damage. A lot of people were exposed. It depended on which area you were in. We just happened to be... in specifically Seven Dollar Bay and they were spraying over Fiddler Point and the wind was such that the dispersant came over us. The glasses that I was wearing last year have pock marks in them where the stuff hit me. The lady that I had in my boat had on a nylon windbreaker and she had holes in her windbreaker. The gel coat on my boat blistered... and 
that's the stuff we breathed... But I have $80 \%$ lung volume as opposed to pre-oil spill I was running 90 to $95 \%$ lung volume. Because pre-oil spill I could pass the physical to get my license...post-oil spill, I have yet to pass the physical so my license is still suspended. So, I cannot earn my living as a charter fisherman.... My medical claims so far have been denied because I refused to see the BP physician on the advice of my pulmonary specialist in Arkansas.

Uncertainty, whether personal or more general, was a prevailing concern. This same type of concern over the extent of damage to the ecosystem and how long the negative effects would last was addressed in our earlier work (Lyon et al. 2015). However, some fishers and their family members have other health concerns that are of a different nature than chemical exposure to oil fumes and dispersant chemicals. In particular, spill-related threats to behavioral health include stress-related challenges to physical and emotional well-being, as demonstrated in the following excerpts:

318: And one of the reasons I told him I married him was because he would make me laugh. He would make me laugh. But with this, he was drinking more because you do not know what the future holds now...And when he drinks and then he starts... he has cried before and then he is like, "I do not even know what is going to happen."

330: He [my husband] is laid back. He has always been laid back and since the storm, I mean since the oil spill and the storm he has had panic attacks. Since the BP oil spill, now he takes medicine to calm his nerves every now and then. It is just sad. It is hard to see him like that sometimes.

313: We lost our quality of life. And so soon after Katrina and Rita. It is like the double whammy. 326: It could possibly be more devastating than what Katrina was to us. You know, I knew after Katrina that one day, as far as from the fishing industry and that, everything would be fine. But as I told you the first day that nobody knows what the effects of this [BP oil spill] is.

331: My dad's going through it. My dad's on the verge of having a heart attack everyday because he's so stressed out about it. That just really aggravated me.

Many of those that took part in the clean-up were exposed to the oil slicks, the dispersant, burning oil, or some combination of toxins. This was highly variable between people, and frightening for those exposed at high rates. Some participants reported:

345: Some people...did a lot of good work. Like you said, because of that chemical explosion, some guy is showing tiredness. And 60 straight days out there they wouldn't let him come in, wouldn't let the boat come in. Washed his clothes for him and everything and kept that boat out there. And he was in the heavy duty crude stuff. And it's going to be interesting to see if he [has] any kind of effects down the line from that. He was in the heart of the battle. He wanted to quit, they wouldn't let him quit. They said, "No, you signed a contract." I did 30 days on a boat. Ain't no way I could do 2 months. But they weren't just sick and stuff, they were tired of working. But it paid off, so let's just hope his health stays up. He's a man with six kids. Young kids.

356: Yes. My brother, Albert, he and Dad, worked for oil spill. My brother Albert got something on his hands from that while at work. He got something on his hands and went to the hospital and he never did come out [Albert died].

Traumatic stress associated with the BP oil spill reportedly took its toll on commercial fishers and their families who are economically dependent on seafood as a source of income. This stress from uncertainty is discussed in greater detail elsewhere (Lyon et al. 2015). Perhaps less obvious, but nonetheless a worrisome prospect, is the potential long-term loss of fishing as a means to making a living. Fishers of Isleños and Croatian descent have been catching shrimp and harvesting oysters in the Gulf of Mexico since the 18th century (for discussion, see Cherry et al. 2015a). The longevity of fishing as a lifestyle in south Louisiana - and worries related to its potential loss - are captured succinctly in this quote:

313: It is more than just a job. You feel like if we are the generation that loses this, then we are responsible for losing our heritage.

Whether the present generation of fishers in south Louisiana will be the final one or not remains to be seen. What is certain is that those who do make it and manage to thrive, despite economic, financial, and health-related adversities, will provide models of resilience.

\section{Discussion}

Over the past decade, residents of the U. S. Gulf Coast have experienced multiple disasters, beginning with the catastrophic 2005 Hurricanes Katrina and Rita, the 2008 Hurricanes, 
Gustav and Ike, and most recently the 2012 Hurricane Isaac. The 2010 Deepwater Horizon Oil Spill has had a devastating effect on Gulf Coast residents, especially those with commercial ties to renewable resources who are also recovering from the 2005 Hurricanes Katrina and Rita (Cherry et al. 2015; Lee and Blanchard 2012; Osofsky and Osofsky 2013; Osofsky et al. 2011). Other evidence has shown that symptoms of posttraumatic stress disorder (PTSD) were associated with previous hurricanes and oil spill exposure in children and adolescents (Osofsky et al. 2014). Addressing the long-term effects of cumulative adversities associated with natural and technological disaster exposure from a lifespan perspective is an important challenge for researchers and mental health professionals (Cherry et al. 2015a; Osofsky et al. 2010; Osofsky and Osofsky 2013)

In our earlier qualitative work (Lyon et al. 2015), we addressed the environmental impacts of the oil spill and cumulative hardships faced by commercial fishers whose lifestyles and traditions are deeply tied to the water. In this study, we build on our earlier work by presenting the four themes in connection with the economic impact, financial hardships, and long-term threats to health and lifestyle based on qualitative analyses of indirectly affected coastal residents and commercial fishers' narrative responses within the first 2 years of the spill. Three of the themes presented here relate to economic and financial hardships and worries. The fourth theme relates to perceived threats to health and stress associated with an uncertain future - and pronounced concerns regarding the preservation of cultural heritage related to fishing. Palinkas (2014) has made the point that qualitative methodologies elicit the perspective of those individuals who are being studied and thus compliment the breath of evidence that quantitative methods provide. Accordingly, the four themes presented here offer texturally rich insights into the lived experience of coastal residents and fishers that complement Gill et al. (2012), where vulnerability variables (commercial ties to renewable resources, oil spill exposure), resource loss (economic damage and future economic concerns), risk perception (family health concerns), and age predicted psychological stress in coastal residents of south Alabama within the first 5 months of the spill. Our findings, among others (Arata et al. 2000; Gill et al. 2012 and Gill et al. 2014; Lee and Blanchard 2012), underscore the heuristic value of Hobfoll's Conservation of Resources theory (Gerhart et al. 2015), suggesting that COR may be a useful conceptual framework to guide future research and the development of interventions to mitigate oil spill-related adversities (see also Palinkas 2012, for related discussion).

On a broader note, the present findings provide new insight into the multidimensional impacts of the oil spill on directly impacted commercial fishers and their families and also among indirectly affected people in the community in which they live. Use of qualitative methods and the inclusion of coastal residents (non-fishers) are strengths of this study, permitting greater depth of understanding of the social impacts and community-wide concerns about the long-term effects of the oil spill. However, the themes presented here and elsewhere (Lyon et al. 2015) should be interpreted in light of at least three methodological limitations. First, these structured interviews were conducted at one point in time. Future research with at least three points of reference would be desirable to examine possible changes in vulnerability and trajectories of resilience over time (Cherry and Galea 2015). Second, a selection bias may be in operation, because people in poor health or marginal living circumstances may not choose to participate in a study on disaster recovery. Third, the emergent themes are based on personal accounts, which are subject to possible biases and unintentional distortions in autobiographical recall of traumatic experiences (Dekel and Bonnano 2013).

In closing, we reiterate the central messages of economic impact, financial losses, health concerns, and threat to cultural heritage (especially those who fish for a living) as conveyed by participants in the wake of the BP oil spill. Primary data revealed common concerns shared by all of the coastal residents as the broader community works to cope with the longterm aftermath of the worst marine oil spill in United States history. These real-life stories attest to the need for continued assessment and evidence-based intervention to lessen distress in the years following catastrophic disasters.

Acknowledgments We are grateful to George Barisich, President of the United Commercial Fishermen's Association, for his help with recruitment and Frank Campo of Campo's Marina in Yscloskey (southeastern St. Bernard) for providing space for interviews. We thank Ashley Cacamo, Annie Crapanzano, and Benjamin Staab for assistance with data collection and Sr. Mary Keefe, Robert Campo, Lauren Denley, Huey Gonzales, Charlie Robin, John Tesvich, and Eva Vujnovich for their contributions to the research effort.

This research was supported by grants from the BP Gulf of Mexico Research Initiative, Office of Research and Economic Development, Louisiana State University. This support is gratefully acknowledged.

\section{References}

Arata, C. M., Picou, J. S., Johnson, G. D., \& McNally, T. S. (2000). Coping with technological disaster: an application of the conservation of resources model to the Exxon Valdez oil spill. Journal of Traumatic Stress, 13(1), 23-39.

Balmer, J. M. T. (2010). The BP deepwater horizon debacle and corporate brand exuberance. Journal of Brand Management, 18, 97-104.

Balmer, J. M. T., Powell, S. M., \& Greyser, S. A. (2011). Explicating ethical corporate marketing insights from the BP deepwater horizon catastrophe: the ethical brand that exploded and then imploded. Journal of Business Ethics, 102, 1-14.

CBS NEWS (2010, September 1, 8:17 PM). BP spent $93 \mathrm{M}$ on advertising after Gulf spill. Retrieved on February 11, 2015 from http://www. cbsnews.com/news/bp-spent-93m-on-advertising-after-gulf-spill/

Cherry, K. E., \& Galea, S. (2015). Resilience after trauma. In D. Ajdukovic, S. Kimhi, \& M. Lahad (Eds.), Resiliency: enhancing 
coping with crisis and terrorism (pp. 35-40). NATO Science for Peace and Security Series, Netherlands: Ios Press.

Cherry, K. E., Marks, L. D., Adamek, R., \& Lyon, B. A. (2015a). Younger and older coastal fishers face catastrophic loss after hurricane Katrina. In K. E. Cherry (Ed.), To appear in traumatic stress and long-term recovery: coping with disasters and other negative life events. New York, NY: Springer.

Cherry, K. E., Sampson, L., Nezat, P. F., Cacamo, A., Marks, L. D., \& Galea, S. (2015b). Long-term psychological outcomes in older adults after disaster: relationships to religiosity and social support. Aging \& Mental Health, 19(5), 430-443.

Cherry, K. E., Sampson, L., Nezat, P. F., Galea, S., Marks, L. D., \& Lyon, B.A. (2015). Prior hurricane and other lifetime trauma predict coping style in older commercial fishers after the BP Deepwater Horizon oil spill. Journal of Applied Biobehavioral Analysis, (in press).

Cope, M. R., Slack, T., Blanchard, T. C., \& Lee, M. R. (2013). Does time heal all wounds? Community attachment, natural resource employment, and health impacts in the wake of the BP deepwater horizon disaster. Social Science Research, 42, 872-881.

Dekel, S., \& Bonnano, G. A. (2013). Changes in trauma memory and patterns of posttraumatic stress. Psychological Trauma: Theory, Research, Practice and Policy, 5, 26-24.

Gerhart, J., Canetti, D., \& Hobfoll, S. (2015). Traumatic stress in overview: definition, context scope, long-term outcomes. In K. E. Cherry (Ed.), To appear inTraumatic stress and long-term recovery: coping with disasters and other negative life events. New York, NY: Springer.

Gill, D. A., Picou, J. S., \& Ritchie, L. A. (2012). The Exxon Valdez and BP oil spills: a comparison of initial social and psychological impacts. American Behavioral Scientist, 56(1), 3-23.

Gill, D. A., Ritchie, L. A., Picou, J. S., Langhinrichsen-Rohling, J., Long, M. A., \& Shenesey, J. W. (2014). The Exxon and BP oil spills: a comparison of psychosocial impacts. Natural Hazards. doi:10.1007/ s11069-014-1280-7.

Grattan, L. M., Roberts, S., Mahan, W. T., Jr., McLaughlin, P. K., Otwell, S., \& Morris, J. G., Jr. (2011). The early psychological impacts of the deepwater horizon oil spill on Florida and Alabama communities. Environmental Health Perspectives, 119(6), 838-843.

Lee, M. R., \& Blanchard, T. C. (2012). Community attachment and negative affective states in the context of the BP deepwater horizon disaster. American Behavioral Scientist, 56(1), 24- 47.

Lyon, B. A., Nezat, P. F., Marks, L. D., \& Cherry, K. E. (2015). When multiple disasters strike: Louisiana fishers in the aftermath of hurricanes and the British petroleum deepwater horizon oil spill. In $\mathrm{K}$. E. Cherry (Ed.), To appear in traumatic stress and long-term recovery: coping with disasters and other negative life events. New York, NY: Springer.

Marks, L. D., Cherry, K. E., \& Silva, J. L. (2009). Faith, crisis, coping, and meaning making after Katrina: a qualitative, cross-cohort examination. In K. E. Cherry (Ed.), Lifespan perspectives on natural disasters: coping with Katrina, Rita and other storms (pp. 195215). New York, NY: Springer.

McCauley, L. A. (2010). Will the BP oil spill affect our health? American Journal of Nursing, 110(9), 54-56.

Mong, M. D., Noguchi, K., \& Ladner, B. (2012). Immediate psychological impact of the deepwater horizon oil spill: symptoms of PTSD and coping skills. Journal of Aggression, Maltreatment \& Trauma, 21, 691-704

Osofsky, H. J., \& Osofsky, J. D. (2013). Hurricane Katrina and the gulf oil spill: lessons learned. The Psychiatric Clinics of North America, 36(3), 371-383.

Osofsky, H. J., Palinkas, L. A., \& Galloway, J. M. (2010). Mental health effects of the gulf oil spill: mental health effects. Disaster Medicine and Public Health Preparedness, 4(4), 3-5.

Osofsky, H. J., Osofsky, J. D., \& Hansel, T. C. (2011). Deepwater horizon oil spill: mental health effects. Disaster Medicine and Public Health Preparedness, 5(4), 280-286.

Osofsky, H. J., Osofsky, J. D., Weems, C. F., Hansel, T. C., \& King, L. S. (2014). Effects of stress related to the gulf oil spill on child and adolescent mental health. Journal of Pediatric Psychology. Advanced Online Publication. doi:10.1093/jpepsy/jsu085.

Palinkas, L. A. (2012). A conceptual framework for understanding the mental health impacts of oil spills: lessons from the Exxon Valdez oil spill. Psychiatry, 75(3), 203-222.

Palinkas, L. A. (2014). Qualitative and mixed methods in mental health services and implementation research. Journal of Clinical Child and Adolescent Psychology, 43(6), 851-861. doi:10.1080/15374416. 2014.910791.

Palinkas, L. A., Petterson, J. S., Russell, J., \& Downs, M. A. (1993). Community patterns of psychiatric disorders after the Exxon Valdez oil spill. American Journal of Psychiatry, 150(10), 1517-1523.

Silva, J. L., Marks, L. D., \& Cherry, K. E. (2009). The psychology behind helping and prosocial behaviors: an examination from intention to action in an adult population. In K. E. Cherry (Ed.), Lifespan perspectives on natural disasters: coping with Katrina, Rita and other storms (pp. 219-240). New York, NY: Springer.

Slife, B. D., \& Williams, R. N. (1995). What's behind the research? Hidden assumptions in the behavioral sciences. Thousand Oaks, CA: Sage.

Solomon, G. M., \& Janssen, S. (2010). Health effects of the gulf oil spill. Journal of the American Medical Association, 16, 2010. doi:10. 1001/jama2010.1254.

Strauss, A., \& Corbin, J. (1998). Basics of qualitative research: techniques and procedures for developing grounded theory. Thousand Oaks, CA: Sage.

Tausch, C., Marks, L. D., Brown, J. S., Cherry, K. E., Frias, T., McWilliams, Z., \& Sasser, D. (2011). Religion and coping in the aftermath of hurricanes Katrina and Rita: qualitative themes from the Louisiana healthy aging study. Journal of Religion, Spirituality, and Aging, 23, 236-253. 